[When citing this chapter, refer to Behaviour 152 (2015) 335-357]

\title{
Non-reciprocal but peaceful fruit sharing in wild bonobos in Wamba
}

\author{
Shinya Yamamoto ${ }^{\mathrm{a}, \mathrm{b}, *}$ \\ ${ }^{a}$ Graduate School of Intercultural Studies, Kobe University, 1-2-1 Tsurukabuto, Nada-ku, \\ 657-8501 Kobe, Japan \\ ${ }^{\mathrm{b}}$ Wildlife Research Center, Kyoto University, Yoshida-honmachi, Sakyo-ku, \\ 606-8501 Kyoto, Japan \\ *Author's e-mail address: shinyayamamoto1981@gmail.com
}

Accepted 30 December 2014; published online 29 January 2015

\begin{abstract}
Food sharing is considered to be a driving force in the evolution of cooperation in human societies. Previously postulated hypotheses for the mechanism and evolution of food sharing, e.g., reciprocity and sharing-under-pressure, were primarily proposed on the basis of meat sharing in chimpanzees. However, food sharing in bonobos has some remarkably different characteristics. Here I report details pertaining to fruit sharing in wild bonobos in Wamba based on 150 events of junglesop fruit sharing between independent individuals. The bonobos, primarily adult females, shared fruit that could be obtained individually without any cooperation or specialized skills. There was no evidence for reciprocal exchange, and their peaceful sharing seems to contradict the sharing-under-pressure explanation. Subordinate females begged for abundant fruit from dominants; this might indicate that they tested the dominants' tolerance based on social bonds rather than simply begging for the food itself, suggesting existence of courtesy food sharing in bonobos.
\end{abstract}

\section{Keywords}

bonobo, Pan paniscus, plant-food sharing, courtesy food sharing, begging for social bond, prosocial behaviour, reciprocity, sharing-under-pressure.

\section{Introduction}

Food sharing is one of the most prevalent forms of prosocial behaviour in the animal kingdom, and it has attracted much attention in investigations of the evolution of cooperation. Why does the owner relinquish food rather than keep it? This is the most basic and common question when discussing the evolution of apparently non-self-rewarding acts. Sharing with dependent related offspring is relatively common in various animal taxa (Clutton-Brock, 
1991; Ydenberg, 1994; Brown et al., 2004), and its evolution can be explained by kin selection (Hamilton, 1964). In contrast, sharing among independent individuals is far less common and the benefit of sharing is often questioned or is controversial (Stevens \& Gilby, 2004; Jaeggi \& van Schaik, 2011). Considerable efforts have been made to find answers for these questions regarding the mechanism and evolution of food sharing by investigating non-human primates, particularly chimpanzees (Pan troglodytes).

To explain non-kin sharing, two main hypotheses have been proposed on the basis of previous studies involving chimpanzees: reciprocity and harassment. The reciprocity hypothesis explains that animals share in exchange for a past or future benefit (e.g., receiving the same food items or a different currency such as coalitions or mating). This hypothesis is supported by previous studies on chimpanzees, which detected statistical associations between sharing food with socially established partners (de Waal, 1989a, 1997; Mitani \& Watts, 2001; Hockings et al., 2007; Gomes \& Boesch, 2009). In contrast, the harassment hypothesis explains that there is an immediate benefit for the owner. Thus, when the beggar negatively affects the owner's feeding rate, the owner may give up some food but retain the majority, i.e., sharing to avoid further harassment from the beggar ('sharing-under-pressure': Wrangham, 1975; 'tolerated theft' for human sharing: Blurton Jones, 1984). This hypothesis is supported by some previous observational and experimental studies involving chimpanzees (Stevens, 2004; Gilby, 2006; Gilby et al., 2010), and it provides a more simple and parsimonious explanation for sharing behaviour (Stevens \& Gilby, 2004; Stevens \& Hauser, 2004). However, these two hypotheses are not exclusive and each may partially explain the sharing behaviour of chimpanzees (Jaeggi \& van Schaik, 2011).

Previous studies have been mainly based on meat sharing among chimpanzees (e.g., in Gombe: Teleki, 1973; Goodall, 1986; in Mahale: Kawanaka, 1982; Nishida et al., 1992; in Kibale: Mitani \& Watts, 1999, 2001; and in Tai: Boesch \& Boesch, 1989; Boesch, 1994). Meat is a rare commodity and at some sites might be difficult to obtain without cooperation between individuals (Boesch, 1994). Some researchers have claimed that the contribution of an individual during cooperative hunting can predict the amount of meat they obtain during the following sharing session (Boesch, 1994). This is why sharing is often discussed in relation to hunting cooperation. In a comparative context, adult male chimpanzees at Bossou often enter 'risky' parts of their habitat to acquire large cultivated foods. In these cases, only a few 
'brave' adult males could be fruit owners, and they consequently share these difficult-to-obtain foods with other community members (Hockings et al., 2007; Ohashi, 2007). The evolutionary story of human sharing cooperation has been constructed on the basis of these studies involving chimpanzees, frequently using comparisons with human hunter-gatherers.

The bonobo (Pan paniscus) is the sister species of the chimpanzee; however, it has been much less studied in this context, although previous studies have reported considerable differences in food sharing between these two species (Kano, 1980; Kuroda, 1980, 1984; White, 1994; Fruth \& Hohmann, 2002). The unique features of sharing in bonobos are particularly characterized by their frequent fruit sharing and female participation in this social interaction. These sharing traits of bonobos are clearly different from the hunting-sharing observed in chimpanzees. A previous study involving wild bonobos in Lomako forest suggested that sharing under pressure, or mutualism, is a more plausible explanation than reciprocity (Fruth \& Hohmann, 2002) because sharing increased with the number of beggars. Lomako bonobos might allow a few recipients to take pieces of food in order to avoid other begging hands; thus, both the owner and recipients seem to be mutually benefited. Meanwhile, detailed video analysis of meat and fruit sharing by a specific dyad of non-kin adult female bonobos in Wamba forest suggested that neither reciprocity nor harassment appeared to completely explain the observations (Hirata et al., 2010). More specifically, reciprocity cannot explain why the owner only tolerated the transfer of non-valuable parts, because it would be more reasonable from a psychological viewpoint to assume that the owner would share the valuable parts if he/she expected a future return benefit. Likewise, harassment cannot fully explain the differential rate of food transfer (more transfers of fruit than of meat), when the degree of pressure given by the recipient toward the two types of food remained more or less constant (Hirata et al., 2010). At present, considering that sufficient quantitative data are not available, it seems too early to make any conclusions regarding the mechanisms underlying fruit sharing in bonobos. We should also consider that the environments where animals live may influence the nature of food sharing. Unfortunately, to my knowledge, no specific study has previously compared food sharing in different wild bonobo sites. In captivity, experiments with chimpanzees and bonobos in African sanctuaries suggested that bonobos are more tolerant of each other than of chimpanzees, where they outperformed chimpanzees in a coopera- 
tive task and subsequent co-feeding (Hare et al., 2007). The bonobos even exhibited a preference for voluntary food sharing rather than eating alone with monopolisable food sources (Hare \& Kwetuenda, 2010), even with unfamiliar individuals (Tan \& Hare, 2013). However, an experimental study with chimpanzees and bonobos in several European zoos reported the opposite; chimpanzees shared food more tolerantly, actively and reciprocally than bonobos who demonstrated a more despotic nature (Jaeggi et al., 2010a). The environments in the zoos and sanctuaries may have affected the results, although we currently do not know what exactly might determine this difference. Therefore, bonobo-chimpanzee comparisons as well as comparisons between same-species communities are required from both captive and wild contexts to understand the complexities of ape sharing behaviours. In this sense, comparisons between bonobo field sites where food sharing can be frequently observed are important to obtain ecological insights into the nature of food sharing.

So far, however, insufficient data are available on food sharing among fully identified wild bonobos in their natural environment. Therefore, the main aim of the present study was to obtain details of fruit sharing in wild bonobos in Wamba forest, where long-term research (since 1973) has established a tracking record that began 1976 and allows for individual identification. Thus, I could investigate the detailed social relationships among sharing individuals. The excellent observational conditions and rich environment with abundant junglesop (Anonidium mannii) fruit also allowed me to focus on a single fruit species in the quantitative data analysis, thereby avoiding possible confusion due to different food types, which may affect the characteristics of sharing (Kano, 1980; Kuroda, 1984; White, 1994; Fruth \& Hohmann, 2002; Hirata et al., 2010).

The shared item, i.e., abundant fruit and not rare meat, also raises the following question: why do independent recipients beg for fruit from other individuals when it can be obtained without any cooperation or specialized skills? The previous hypotheses, i.e., reciprocity and harassment, assume nutritional benefits to the recipients and discusses the benefits accrued to individuals that share (Stevens \& Gilby, 2004). However, if the begging individual could acquire more of the same food by implementing an alternate strategy, another perspective may be required to understand this sharing behaviour (Slocombe \& Newton-Fisher, 2005). The target in the present study, i.e., junglesop fruit, is often available in small quantities simultaneously, but it can still be found much more frequently and in greater quantities in Wamba 
than meat in the chimpanzee studies and Treculia fruit in the bonobo studies in Lomako. In the high season for junglesop fruits in Wamba, I counted a maximum of nine individuals who ate junglesop fruits simultaneously at a feeding site, and up to 45 individuals in total during a single observation day (Yamamoto, unpublished data), although on average 0.49 Treculia fruits were eaten per day in Lomako (Fruth \& Hohmann, 2002). On the basis of these quantitative data, I examined some previously postulated hypotheses and propose another hypothesis from the recipient's perspective to explain this sharing behaviour and its evolution.

\section{Materials and methods}

\subsection{Study conditions}

I studied bonobos in the E1 group at Wamba $\left(0^{\circ} 11^{\prime} 08^{\prime \prime} \mathrm{N}, 22^{\circ} 37^{\prime} 58^{\prime \prime} \mathrm{E}\right)$ in the northern sector of the Luo Scientific Reserve, Democratic Republic of Congo. The E1 group size varied between 27-31 individuals during the study periods, including 9-10 adult/adolescent females, 8-10 adult/adolescent males, 1-2 juvenile females, $2-3$ juvenile males and 6-9 dependent infants, during the study periods. These numbers did not include some individuals from other groups who made short-term visits $(<1$ month at the point of study). The age-sex class was based on Hashimoto's (1997) categorization for Wamba bonobos, i.e., age < 4: infant, 4-7: juvenile, 8-14: adolescent, $\geqslant 15$ : adult; and I adjusted it for the purpose of the present study. In the present study, the distinction between a dependent infant and a juvenile was based on whether an individual was carried by his/her mother or walked independently for $>20 \mathrm{~m}$ during travel on the ground. In this sense, a juvenile can be considered as an 'independent individual' who could obtain his/her food by him/herself. The age when the transition occurred was approximately 4 years. I categorized a young female as juvenile if she remained in her natal group. Corresponding to this categorization of females, I used females' average emigration age, i.e., 8 years (Furuichi, 1989; Hashimoto, 1997; Furuichi et al., 1998, 2012; Hashimoto et al., 2008), for the categorization of males into juveniles and adults. The distinction between adolescent and adult is not that meaningful for the present study; hence, hereafter both classes have been taken together as adult. In this study, I focused on sharing among independent individuals, i.e., within and between adults and juveniles. Not all of the individuals lived in the community simultaneously (some vanished or emigrated, whereas others immigrated or matured), but 315 dyads of in- 
dependent individuals were considered. For each age-sex class ratio and relevant analyses, I used the median number of individuals in each age-sex class during the study period, with a total of 22 independent individuals, i.e., 10 adult females (45.5\%), nine adult males (40.9\%), one juvenile female $(4.5 \%)$ and two juvenile males $(9.1 \%)$. All individuals in the group were well identified and habituated. Artificial provisioning was abolished in 1996. The history of the E1 group and the details of the study site have been previously described by Kano (1992), Furuichi et al. (1998, 2012), Hashimoto et al. (2008) and Idani et al. (2008).

\subsection{Data collection and analysis}

I collected sharing data ad libitum by direct observations and occasionally with video cameras during four field seasons (July-August 2010, JuneAugust 2011, September-November 2012 and August-September 2013) when there was a relatively high availability of junglesop fruit. During these periods, the bonobos normally move around in a large party that comprises most group members. If they split into separate parties, I attempted to follow the larger party. In the present study, in order to avoid possible confusion caused by different food types, I focused on the sharing of junglesop fruit, although I collected sharing data for any food type as far as possible, which will be analysed more in detail in future studies. A junglesop fruit is typically $40-50 \mathrm{~cm}$ in length and weighs $4-6 \mathrm{~kg}$ (Figure 1a). This fruit is easy to process and bonobos consume soft flesh around big seeds. They normally spat out the seeds which sometimes have fresh remains around them (Figure 1b). This junglesop fruit is one of the most frequently shared food items among Wamba bonobos (Kano, 1980; Kuroda, 1984).

I defined food sharing as the unhampered transfer of food from A (the owner) to B (the recipient) (Kano, 1980; Kuroda, 1984; Feistner \& McGrew, 1989). I excluded transfers in which there was no clear possession, such as collecting scraps in the vicinity of a feeding individual. A sharing event was recorded when one food item was divided between two individuals (ownerrecipient dyad), which sometimes comprised two or more transfers of small portions divided from a single food item. Therefore, multiple transfer types could be observed in a single sharing event. If one food item was shared with several recipients, one event was recorded for each owner-recipient dyad. For example, when A shared a fruit with B and C, I counted two events (A$\mathrm{B}$ and $\mathrm{A}-\mathrm{C})$; if $\mathrm{A}$ shared a fruit with $\mathrm{B}$, and then $\mathrm{B}$ shared his/her gain with $\mathrm{C}$, I counted two events (A-B and B-C). 


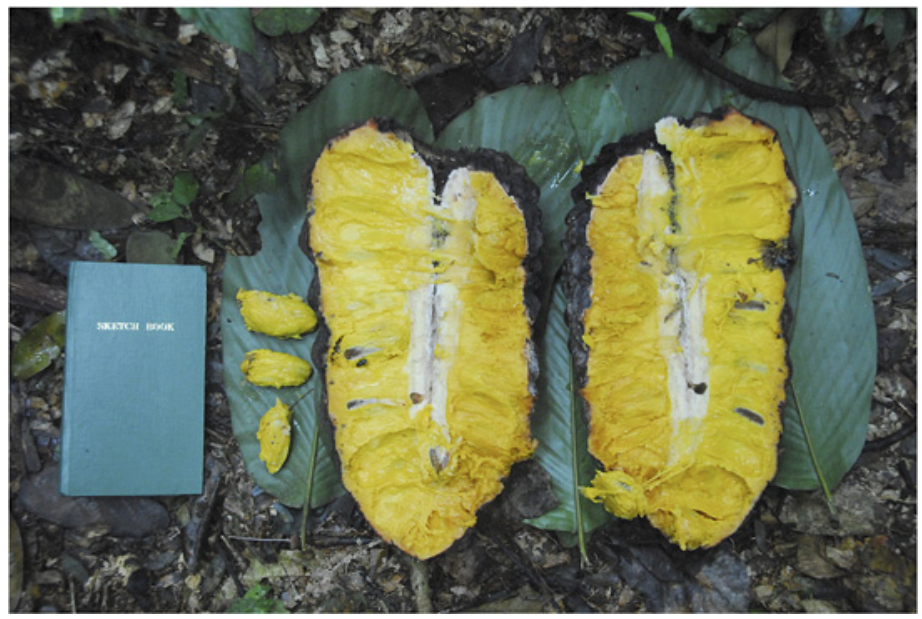

(a)

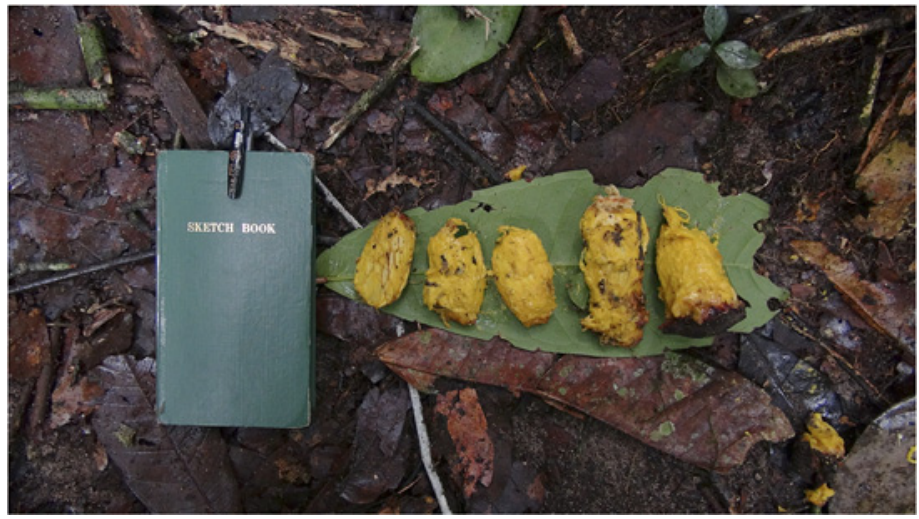

(b)

Figure 1. (a) Junglesop (Anonidium mannii) fruit, and (b) its remains after a bonobo ate the fruit. Some flesh remained around the seeds (photo by Shinya Yamamoto). This figure is published in colour in the online edition of this journal, which can be accessed via http:// booksandjournals.brillonline.com/content/journals/1568539x.

Based on Jaeggi et al. (2010b) and other psychological experimental studies of ape prosociality (Ueno \& Matsuzawa, 2004; Warneken et al., 2007; Yamamoto et al., 2009, 2012), I examined which individual, the owner or recipient, initiated food transfer. Food transfer was categorized into three types: proactive transfer (offering), which was initiated by the owner in the absence of the recipient's begging; reactive transfer where the owner facilitated tak- 
ing upon the recipient's begging; and passive transfer where the owner did not facilitate taking but they simply tolerated the recipient's taking.

I recorded 'begging' when the recipient reached for the owner's food when it was in his/her hands, feet or mouth. Close observation (identical to 'staring' in Kuroda (1984) and 'peering' in Furuchi (1989)) was often included in the category of 'begging' in previous studies (Fruth \& Hohmann, 2002; Gilby, 2006). However, I excluded this from my 'begging' category because (1) close observation has almost no effect on the soliciting of sharing (Kuroda, 1984; Furuchi, 1989); (2) the animals might only be interested in the item in another individual's hand without having any intention of taking it and (3) close observation is also conspicuous in other contexts, particularly during social learning in apes (e.g., Yamamoto et al., 2013), and therefore, the function and motivation of close observation seems ambiguous. I also recorded the body part (hand or mouth) from which the recipient obtained their share, which corresponded to whether sharing occurred before or after the transferred part was chewed or licked by the owner. Even after the owner chewed or licked the fruit, some edible flesh sometimes still remained around the seed, which could be transferred to the recipient. The shared portion size was also categorized as smaller ('small portion') or larger ('large portion') than the recipient's hand. Any social interactions before, during and after sharing were analysed, where the main targets of this analysis were agonistic interactions, genito-genital $(\mathrm{G}-\mathrm{G})$ rubbing and copulation.

With respect to the social relationship between an owner and a recipient, I considered two key factors: kin relationships (mother-offspring and brothers or sisters, but not father-offspring since no genetic information is available for this at this moment) and pairwise dominance relationships. Assessments of dominance relationships were based on the outcomes of dyadic agonistic interactions and non-agonistic displacement (approach-retreat). With the help of experienced local assistants, I confirmed dominant-subordinate relationships only when their evaluations and my own observations were in complete agreement. If the evaluations did not completely agree for a given pair of individuals, I considered that the dominance relationship between them was ambiguous.

Statistical analyses were performed using $\mathrm{R}$ version 3.0.3 (R Core Team, 2014) except for matrix analysis which was done with MatrixTester version 2.2.4 developed by Hemelrijk (1990). I generally analysed all the sharing events between independent individuals; when I paid attention to sharing between non-kin individuals, I recorded this as 'non-kin sharing'. 


\section{Results}

Among independent individuals in the E1 group in Wamba, I recorded a total of 178 sharing events with 17 food types including fruit, other plant food, honey and meat of small animals (Table 1). The sharing of junglesop fruit accounted for $84.3 \%$ of these events (150 sharing events); thus, I focused on interactions related to junglesop fruit.

\subsection{Junglesop fruit eating}

The junglesop fruit was obtained independently by individuals (i.e., not through sharing from others) 901 times in total. The field seasons of 2010, 2011 and 2013 occurred during the high season for junglesop fruit, whereas the field season of 2012 occurred after the high season (Table 2). All of the age-sex classes consumed junglesop fruit (Tables 3 and 4), although the adult females consumed them more frequently and the adult males and juveniles consumed them less than expected, based on the number of individuals

\section{Table 1.}

Shared food types among independent individuals observed in the Wamba E1 group.

\begin{tabular}{llllr}
\hline Species & Local name & Food type & Size of food & No. of events \\
\hline Anonidium mannii & Bolingo & Fruit & Big & 150 \\
Treculia africana & Boimbo & Fruit & Big & 6 \\
Anomalurus spp. & Itere & Meat & Big & 3 \\
Saba florida & Bossenda & Fruit & Big & 2 \\
Brachystegia laurentii & Langa & Fruit (seed) & Big (small) & 2 \\
Cola chlamydantha & Bokotikoti & Fruit & Small & 2 \\
$?$ & Botete & Fruit & Small & 2 \\
Meliponinae spp. & Liutsu & Honey & Big & 2 \\
Isolona congolana & Bofiningo & Fruit & Small & 1 \\
Musanga cecropioides & Bombambo & Fruit & Small & 1 \\
Dialium pachyphyllum & Elimilimi & Fruit & Small & 1 \\
Dacryodes edulis & Bosou & Fruit & Small & 1 \\
Parkia bicolor & Lilembe & Fruit & Small & 1 \\
Pancovia laurentii & Botende & Fruit & Small & 1 \\
Landolphia owariensis & Batofe & Fruit & Small & 1 \\
Raphia sp. & Bolilo & Pith & Big & 1 \\
Guarea laurentii & Litoku & Pith & Big & 1 \\
Total & & & & 178 \\
\hline
\end{tabular}

The species identification of plant food referred to Idani et al.'s (1994) plant list. Size was divided into two categories: 'big' (bigger than an individual's hand) or 'small' (smaller than an individual's hand) (see text for details). 
Table 2.

Numbers of junglesop (Anonidium mannii) fruit eaten and shared by independent individuals during each field season.

\begin{tabular}{lcccc}
\hline & Observation days & No. of fruits eaten & No. of fruits shared & Shared/eaten (\%) \\
\hline 2010 & 35 & 337 & 54 & 16.0 \\
2011 & 37 & 347 & 56 & 16.1 \\
2012 & 37 & 2 & 2 & 100.0 \\
2013 & 20 & 215 & 13 & 6.1 \\
Total & 129 & 901 & 125 & 13.9 \\
\hline
\end{tabular}

in each age-sex class (age-sex class, observed versus expected: adult female, 531 versus 409.5; adult male, 290 versus 368.6; juvenile female, 12 versus 41.0; juvenile male, 68 versus $81.9 ; \chi^{2}=75.6$, $\mathrm{df}=3, p<0.01$ ). The edible ripe fruits could normally be found on the ground. In a typical case, an individual who found a fruit on the ground first checked the inside of the fruit by breaking it, and if it was good, he/she took a part of it away (normally $1 / 4-3 / 4$, but taking an entire fruit was rare) or started eating it at the site. Occasionally, another individual took some of the remaining fruit later. I observed 14 cases where two individuals (adult females in each case) arrived and touched a fruit almost simultaneously before dividing it. These cases generated a tension between the participants, resulting in $\mathrm{G}-\mathrm{G}$ rubbing between them (13/14 cases), which is considered to be a tension-reducing behaviour, although physically agonistic interactions were never observed. I did not count these cases as sharing because the ownership of the fruit was ambiguous at that point and the fruit was not directly transferred between individuals.

\subsection{Junglesop fruit sharing}

Of the 901 junglesop fruit eaten by the bonobos, $13.9 \%(N=125)$ were shared among two or more independent individuals (Table 2; Figure 2). In total, 150 sharing events were observed, and each fruit was shared with 1.2 recipients on average. There were 95 events $(63.3 \%)$ between non-kin individuals (non-kin sharing) and 55 (36.7\%) between independent kin individuals (sharing between mother and offspring or between brothers). Analysis of the age-sex class of the owners and recipients in all the sharing events showed that adult females account for the majority of either role (Tables 3 and 4). Adult females accounted for $92.7 \%$ of the owners, whereas adult 
Table 3.

Numbers of junglesop (Anonidium mannii) fruit eaten by each age-sex class of independent individuals.

\begin{tabular}{lc}
\hline & Eaten individually (\%) \\
\hline Adult female (median $N=10)$ & $531(58.9)$ \\
Adult male (median $N=9)$ & $290(32.2)$ \\
Juvenile female (median $N=1)$ & $12(1.3)$ \\
Juvenile male (median $N=2)$ & $68(7.5)$ \\
Total & $901(100)$
\end{tabular}

The number of individuals in each age-sex class in the eaten individually group is represented by the median number throughout the study periods. Adult in the present study includes adolescent and adult individuals in the categorization of Hashimoto (1997). See text for details of age-sex categorization.

males accounted for only 7.3\%. Sharing never originated from juvenile individuals. Among the recipients, although juveniles were frequent recipients (juvenile female: $10.7 \%$, juvenile male: $35.3 \%$ ) given the small number of individuals ( $4.5 \%$ and $9.1 \%$, respectively), the frequent adult female recipients $(50.7 \%)$ and much less frequent adult male recipients (3.3\%) were still notable in comparison to their population ratios (45.5 and $40.9 \%$, respectively). In non-kin sharing events, adult females accounted for $89.5 \%$ of the owners ( $10.5 \%$ adult males) and $80.0 \%$ of the recipients $(2.1 \%$ juvenile females; $17.9 \%$ juvenile males; there was no adult male recipient).

\section{Table 4.}

Numbers of junglesop fruit Anonidium mannii shared by each age-sex class of independent individuals.

\begin{tabular}{lccccc}
\hline Shared from & \multicolumn{5}{c}{ To } \\
\cline { 2 - 6 } & $\begin{array}{c}\text { Adult } \\
\text { female }\end{array}$ & $\begin{array}{c}\text { Adult } \\
\text { male }\end{array}$ & $\begin{array}{c}\text { Juvenile } \\
\text { female }\end{array}$ & $\begin{array}{c}\text { Juvenile } \\
\text { male }\end{array}$ & $\begin{array}{c}\text { Total } \\
(\%)\end{array}$ \\
\hline Adult female & 72 & 5 & 16 & 46 & $139(92.7)$ \\
Adult male & 4 & 0 & 0 & 7 & $11(7.3)$ \\
Juvenile female & 0 & 0 & 0 & 0 & $0(0.0)$ \\
Juvenile male & 0 & 0 & 0 & 0 & $0(0.0)$ \\
Total $(\%)$ & $76(50.7)$ & $5(3.3)$ & $16(10.7)$ & $53(35.3)$ & $150(100)$ \\
\hline
\end{tabular}

Adult in the present study includes adolescent and adult individuals in the categorization of Hashimoto (1997). See text for details of age-sex categorization. 


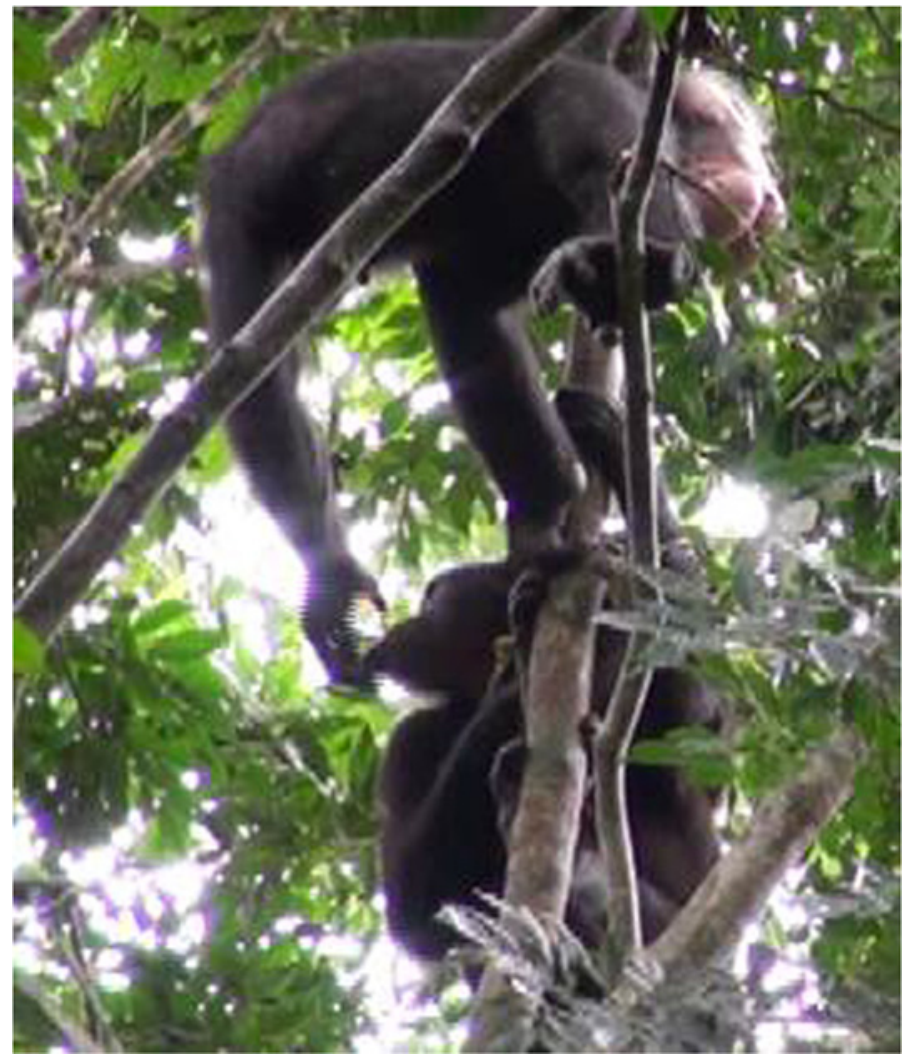

Figure 2. Sharing between adult females. Sl (above) begged for a portion of junglesop (Anonidium mannii) fruit from Nv's mouth (video-still by Shinya Yamamoto). This figure is published in colour in the online edition of this journal, which can be accessed via http:// booksandjournals.brillonline.com/content/journals/1568539x.

No significant relationship was observed between the number of times of individual eating and the number of times of receiving (Pearson's productmoment correlation: $t=1.21, \mathrm{df}=24, p=0.24, R=0.24$; Figure 3 ). Thus, not only individuals who could not obtain junglesop fruit by themselves but also those who could obtain the fruit by themselves became recipients in sharing events.

\subsection{Relationship between owners and recipients}

No significant relationship was observed between the number of times of giving and the number of times of receiving in sharing events (Pearson's product-moment correlation: $t=-0.15$, df $=24, p=0.883, R=-0.03$; 


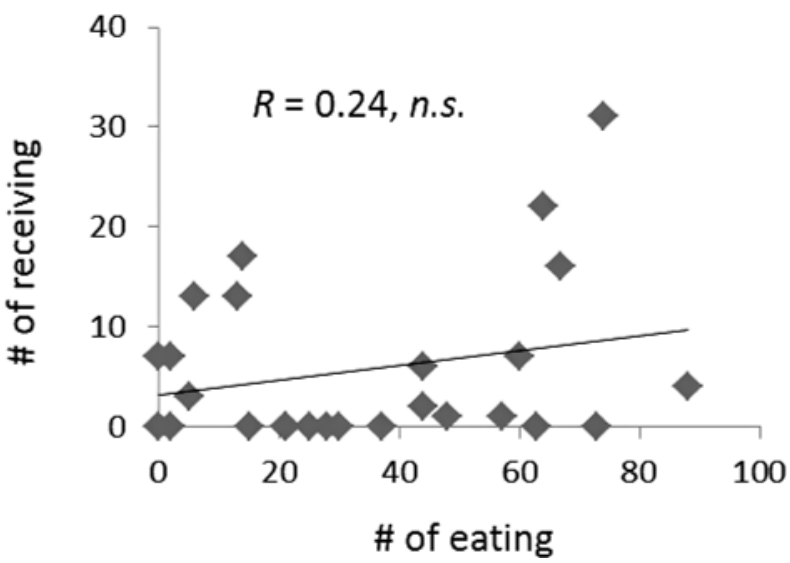

Figure 3. Numbers of times eating junglesop fruits individually and receiving them through sharing. Each dot represents an independent individual.

Figure 4). An adult female (named Hs) frequently gave and received fruits ('A' in Figure 4). However, the analysis of Hs's interacting partners showed that there was no significant overlap among individuals in her giving and receiving interactions. Hs received fruit most frequently from $\mathrm{Yk}$ (10 events), No (five events), Ki and Nv (four events, respectively), while she gave fruit most frequently to Ot (six events), An (three events) and Nv (two events).

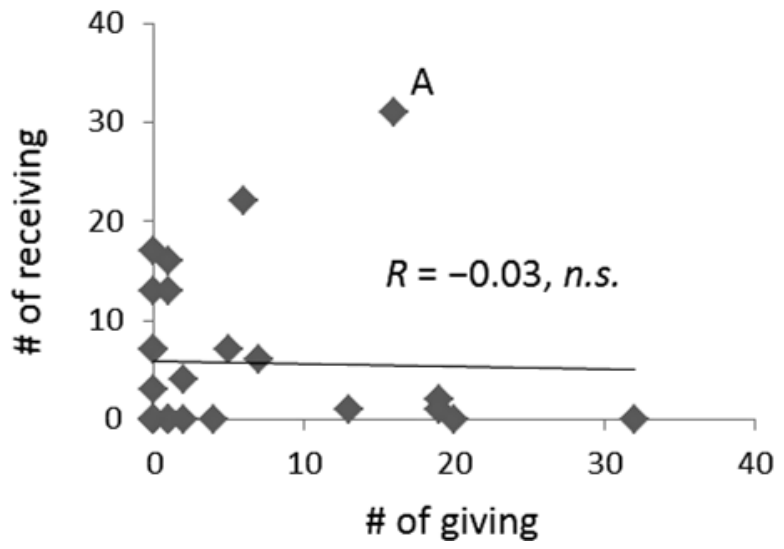

Figure 4. Numbers of times of giving and receiving. Each dot represents an independent individual. No significant correlation was observed between the two. Even for an individual (Hs, indicated by ' $\mathrm{A}$ ' in this figure) who frequently gave and received fruits, the giving and receiving partners did not overlap (see text for details). 
Matrix analysis also showed no evidence for reciprocity. No significant correlation between giving and receiving was found in analyses with all the 150 sharing events $\left(\tau K_{\mathrm{r}}\right.$-test: $\tau K_{\mathrm{r}}=0.068$, permutations $=2000, p_{\mathrm{r}}$ (onetailed probability value in the right tail of the permutation distribution) $=$ 0.22 ) nor with the 95 non-kin sharing ( $\tau K_{\mathrm{r}}$-test: $\tau K_{\mathrm{r}}=0.074$, permutations $=2000, p_{\mathrm{r}}=0.22$ ). I also calculated a giving/receiving ratio for each of the 48 dyads where sharing was observed at least once and found that a giving/receiving score of between 0.5 and 2 (i.e., 'balanced') was observed only in two pairs.

The shared fruit were predominantly transferred from dominants to subordinates. Among 150 sharing events, 129 events (86.0\%) were from dominants to subordinates, $10(6.7 \%)$ were from subordinates to dominants and $11(7.3 \%)$ were between individuals where the dominance relationship was ambiguous.

Next, I examined whether a recipient received fruits from a specific individual. In the E1 group, 14 individuals became recipients in the sharing events: seven adult females, one adult male, two juvenile females and four juvenile males. With the exception of one juvenile male, every juvenile received fruits predominantly from his/her mother (more than half of the fruit they received). The only adult male received fruit four times only from his mother. However, the adult females who were involved in sharing as a recipient more than two times $(N=5)$ did not have such a specific donor. They each received fruits from 6.2 individuals on average $(\mathrm{SD}=1.9)$.

\subsection{Food transfer types}

Analysis of the food transfer types showed that passive transfer was observed in all the 150 sharing events. Reactive transfer occurred in two sharing events $(1.3 \%)$ and proactive transfer occurred in one sharing event $(0.7 \%)$. Multiple transfer types could be recorded during a single sharing event because a single sharing event sometimes contained two or more transfers of small portions divided from one food item. These reactive and proactive transfers were observed only from mother to her offspring when she gave up the remaining food before travelling. Recipients obtained their share from the owners' hand (or foot) in $112(74.7 \%)$ of the sharing events, and from the owners' mouth in 73 events $(48.7 \%)$ after the owners had chewed or licked it. Transfers of small portions were observed in 140 (93.3\%) of the sharing events and transfers of portions larger than the recipient's palm were involved in 16 events $(10.7 \%)$. 


\subsection{Other social interactions}

No physically agonistic interactions were observed during the sharing events. G-G rubbing between adult females was observed during 14 sharing events: two cases occurred before the first food transfer during events and 12 cases after the first transfer. Among the latter cases, five cases were observed after a large portion was taken by a recipient. Male-female copulations were observed 16 times during junglesop fruit feeding, and sharing occurred in three of these cases: one sharing event occurred from an adult female to a juvenile male before the copulation, another occurred from an adult male to an adult female during the copulation and the other occurred from an adult female to a juvenile male after the copulation. I recorded seven cases where an adult female without any food item copulated with an adult male who held a junglesop fruit in his hand, resulting in no food sharing between them except the above one case.

\section{Discussion}

The present study demonstrates peaceful fruit sharing among wild bonobos in Wamba, non-kin sharing of which predominantly occurred between adult females. In comparison with wild chimpanzees, fruit sharing occurred much more frequently in wild bonobos. The shared fruit was relatively abundant compared to meat, and could be obtained without any cooperation or specialized skills. Bonobos also share meat infrequently, but there is no reported evidence of group cooperation in hunting (Ihobe, 1992; Ingmanson \& Ihobe, 1992; White, 1994; Fruth \& Hohmann, 2002; Hohmann \& Fruth, 2008; Surbeck \& Hohmann, 2008; Hirata et al., 2010). Therefore, the hunting hypothesis, which assumes the successive occurrence of cooperative hunting and food sharing, is not applicable to the sharing of food that occurs among bonobos. In contrast to meat sharing in chimpanzees where a rare and precious food item is shared, more abundant fruits were shared among bonobos. Indeed, the bonobo recipients were not restricted to 'poor' individuals who could not obtain the same fruit by themselves. The bonobos, particularly adult females, could often obtain junglesop fruits by themselves, but they frequently begged for the same food items from others. More or less 'poor' adult males, compared to adult females, seldom begged for fruits from others. This clearly shows that bonobos do not share food because the recipients 
cannot obtain the target food by themselves. This is one of the clear differences from chimpanzees' meat sharing where individuals who could not get prey begged for the precious meat from a successful possessor.

Reciprocity is considered to explain meat sharing among chimpanzees at some sites, but it does not appear to be a good explanation for fruit sharing in bonobos. Neither individual, pairwise, nor group-level analyses of the balance of giving and receiving showed that the bonobos exchanged fruit reciprocally. Although some episodic observations in captivity and in a previous provisioning field in Wamba suggest that bonobos share food in return for sexual favours (Kuroda, 1984; de Waal, 1989b), this does not seem to be a plausible explanation for wild bonobos under natural conditions. The fruits were shared mainly between adult females or between adult females and juveniles, where sexual exchanges cannot be expected. More clearly, adult males with their hands full of fruit were observed to copulate with adult females without any fruit on seven occasions, but they did not share with their mate, except in one case. In addition, sharing-for-alliance is not a plausible explanation either. In Wamba, agonistic interactions are not frequent and supporting behaviours among females (particularly support from a subordinate to a dominant) are not conspicuous, although mothers often support their sons (Kano, 1992; Furuichi, 1997, 2011; for Lui Kotale, also see Surbeck et al., 2011; Surbeck \& Hohmann, 2013; and for Lomako, also see Hohmann \& Fruth, 2003). It appears that food sharing in bonobos is not directed predominantly at alliance formation to the same degree as food sharing in chimpanzees.

The present study shows that neither food-for-food, food-for-sex, nor food-for-alliance reciprocity is a plausible explanation for Wamba bonobos' food sharing, although it does not completely reject the reciprocity hypothesis. The sharers may have gained some benefit. For example, they may have occupied a central position and leadership of the group; thus, they could decide the directions of group movements. Food-for-grooming reciprocity cannot be excluded in the present study, either. However, it seems unlikely that they consciously expected benefits in the future. Hirata et al. (2010) noted that it is more reasonable to assume that the owner would share their valuable commodities if they expected a future benefit in return. The hesitancy of owners, which was represented by their passive attitude with virtually no proactive and reactive sharing, may disprove their expectation of future benefits, which is assumed in the reciprocal hypothesis. 
Peaceful sharing with no physically agonistic interactions between owners and recipients also suggests that the sharing-under-pressure hypothesis does not fully explain food sharing in bonobos in Wamba. The direction of food transfer was predominantly from the dominant to the subordinate. When tensions emerged, they were resolved by G-G rubbing. This often occurred when a recipient took a large portion (still smaller than half of the item held by the owner), and the recipient adopted a posture where she laid on her back as if she was asking for a pardon. Normally, only a single independent individual begged for a single item held by an owner, and the owners could easily avoid the begging from subordinates simply by turning away. There was no obvious case in which a recipient reduced an owner's feeding rate by holding his/her arm. Based on a study in Lomako, Fruth \& Hohmann (2002) suggested that the owners benefited by sharing with only a small number of recipients who assisted them in defending their possession of a Treculia fruit against others. However, this hypothesis does not seem to be applicable to the predominantly dyadic sharing interactions of junglesop fruits (which are smaller than Treculia fruits) in Wamba. Previous studies have reported that more preferred meat attracted more begging (White, 1994) or nearly constant begging (Hirata et al., 2010) from recipients, although this resulted in a lower transfer rate than fruit items. Thus, taking all of these into account, it is plausible that the owners in the present study gained little or no immediate material benefit from sharing.

The most parsimonious explanation for the majority of the fruit sharing events in bonobos in Wamba might be that they shared a surplus. The fruit was much more abundant than meat, which was suggested by the much higher frequency of eating the fruit. As well as the species differences between bonobos and chimpanzees, the present study also suggests that there are differences among the sites where wild bonobos were studied. In comparison with Lomako, Wamba seems to have greater quantities of sharable fruit. In the present study, 7.1 fruits (junglesop) were eaten on average each day during the study period in Wamba (if only the high seasons of 2010, 2011 and 2013 are considered, the number increases to 10.0) and $13.7 \%$ of these were shared among independent individuals. In contrast, 0.49 fruits (Treculia africana) were eaten each day and approximately half of these were shared in Lomako, where junglesop fruits were eaten and shared much less frequently than Treculia fruits (Treculia 93\%, junglesop 7\%) (Fruth \& Hohmann, 2002). In such a rich environment, Wamba bonobos often shared 
only small portions, which the owners may sometimes have already chewed or licked to consume most of the edible part. In Wamba, in typical cases, bonobos who first found a junglesop fruit on the ground only took a part of it but not the whole. The bonobos did not seem to consume the greatest possible amount of the fruit. Therefore, there was little cost when large fruit owners relinquished small portions of the abundant fruit. The nature of sharing, predominantly characterized by passive transfers, also supports the ambiguous underlying psychology of the owners.

This analysis of fruit sharing in bonobos encouraged us to investigate the sharing interactions from the viewpoint of the recipients. It may be interesting to examine the reasons why recipients beg for a fruit from others when they can readily obtain it by themselves. The above hypotheses, reciprocity and sharing-under-pressure, are based on an assumption that food owners relinquish their precious food and that recipients always beg for nutritional gain; however, this does not always seem to suit the bonobos' cases. The access to junglesop fruits was not severely restricted during the study period and even subordinate males who are considered to have the least access priority to food (Furuichi, 1989, 1997; Kano, 1992; White \& Wood, 2007) could eat the fruit without any expectation of sharing. The results show that individuals who consumed many fruits still begged for a share. The female-biased sharing might indicate strong female-female social bonds, as suggested in previous studies (Idani, 1991; Kano, 1992; Furuichi, 2011). It is also possible that the subordinates begged to strengthen social bonds, rather than to obtain the food itself, i.e., 'courtesy' food sharing. Of course, the food itself would still have been attractive to them and this cannot be excluded; however, the begging-for-social bond hypothesis may be a better explanation of begging by subordinates when they could find the fruit by themselves. This has also been suggested anecdotally in previous studies (Kuroda, 1984; Furuichi, 2011; for chimpanzee fruit sharing, see also Slocombe \& NewtonFisher, 2005), but insufficient qualitative and quantitative data and analyses are available at present; thus, further examinations are required to support this hypothesis, i.e., 'courtesy' food sharing characterized by begging-forsocial bond.

In addition to the species differences between bonobos and chimpanzees, the differences between Wamba and Lomako sites seem to be important and merit further detailed analysis. As stated above, there appeared to be considerable differences between the two study sites in terms of the food types 
shared and the sharing frequency, which might have been influenced by possible differences in the fruit and tree compositions between the two forests. At present, however, no exact comparative data are available to address these differences; therefore, this should be examined in future studies. The present study also found that there were remarkable annual differences in the frequency of junglesop fruit sharing in Wamba. In the field seasons of 2010 and 2011, the bonobos shared junglesop fruits frequently (16.0 and 16.1\%, respectively). In 2013, however, they shared the fruit much less frequently (6.1\%). Considering that they consumed many junglesop fruits in each field season (9.6 fruit eaten per observation day in 2010, 9.4 in 2011 and 10.8 in 2013), the amount of fruit available might not be the best explanation for this difference. Other possible influential factors might include changes in food quality and/or social relationships, which were not fully examined. Further analysis of between-site differences and within-site annual changes, as well as species differences, will surely help us understand how different environments and societies facilitate the evolution of sharing cooperation in the animal kingdom, particularly in Pan and humans.

\section{Acknowledgements}

The field observations were certified by the government of DR Congo, and they complied with the current laws of the countries involved, as well as with Guidelines for Studying Wild Primates or Using Wild Primates in Research of Primate Research Institute, Kyoto University. Special thanks to the Research Center for Ecology and Forestry (CREF) and the Ministry of Scientific Research of DR Congo for their research permission; Takeshi Furuichi, Tetsuro Matsuzawa, Tetsuya Sakamaki, Hiroyuki Takemoto, Satoshi Hirata, Nahoko Tokuyama, Heungjin Ryu, Izabel Behncke, Kirsty Graham, Cintia Garai, Kazuya Toda, the local guides and staff at Wamba and the members of CREF and Wamba Committee for Bonobo Research (WCBR) for their fruitful discussion and helpful support during my stay in DR Congo. I am grateful to the staff of Kumamoto Sanctuary of the Wild Research Center, Kyoto University, as well as the staff at the Primate Research Institute, Kyoto University, for allowing me to conduct my field trips. I also thank Brian Hare and two anonymous reviewers for their constructive comments on an earlier version of the manuscript. The present study was supported by grants from the Japanese Society of Promotion Sciences (JSPS: Nos 22800034 and 
40585767 to S. Yammaoto; No. 22255007 and Asia-Africa Science Platform Program 2009-2011 and 2012-2014 to T. Furuichi; and AS-HOPE and ITPHOPE to T. Matsuzawa), Ministry of Education, Culture, Sports, Science, and Technology in Japan (MEXT: Nos 20002001 and 24000001 and MEXT special grant 'Human Evolution' to T. Matsuzawa), and Ministry of the Environment in Japan (The Environment Research and Technology Development Fund D-1007 to T. Furuichi).

\section{References}

Blurton Jones, N.G. (1984). A selfish origin for human food sharing: tolerated theft. — Ethol. Sociobiol. 5: 1-3.

Boesch, C. (1994). Cooperative hunting in wild chimpanzees. - Anim. Behav. 48: 653-667.

Boesch, C. \& Boesch, H. (1989). Hunting behavior of wild chimpanzees in the Taï National Park. - Am. J. Phys. Anthropol. 78: 547-573.

Brown, G.R., Almond, R.E.A. \& van Bergen, Y. (2004). Begging, stealing, and offering: food transfer in nonhuman primates. - Adv. Stud. Behav. 34: 265-295.

Clutton-Brock, T.H. (1991). The evolution of parental care. - Princeton University Press, Princeton, NJ.

de Waal, F.B.M. (1989a). Food sharing and reciprocal obligations among chimpanzees. J. Hum. Evol. 18: 433-459.

de Waal, F.B.M. (1989b). Peacemaking among primates. - Harvard University Press, Cambridge, MA.

de Waal, F.B.M. (1997). The chimpanzee's service economy: food for grooming. — Evol. Hum. Behav. 18: 375-386.

Feistner, A.T.C. \& McGrew, W.C. (1989). Food-sharing in primates: a critical review. — In: Perspectives in primate biology, Vol. 3 (Seth, P.K. \& Seth, S., eds). Today and Tomorrow's, New Delhi, p. 21-36.

Fruth, B. \& Hohmann, G. (2002). How bonobos handle hunts and harvests: why share food? - In: Behavioral diversity in chimpanzees and bonobos (Boesch, C., Hohmann, G. \& Marchant, L., eds). Cambridge University Press, Cambridge, p. 231-243.

Furuichi, T. (1989). Social interactions and the life history of female Pan paniscus in Wamba, Zaire. - Int. J. Primatol. 10: 173-197.

Furuichi, T. (2011). Female contributions to the peaceful nature of bonobo society. - Evol. Anthropol. 20: 131-142.

Furuichi, T. (1997). Agonistic interactions and matrifocal dominance rank of wild bonobos (Pan paniscus) at Wamba. - Int. J. Primatol. 18: 855-875.

Furuichi, T., Idani, G., Ihobe, H., Hashimoto, H., Tashiro, Y., Sakamaki, T., Mulavwa, M.N., Yangozene, K. \& Kuroda, S. (2012). Long-term studies on wild bonobos at Wamba, Luo Scientific Reserve, D.R. Congo: towards the understanding of female life history in a male-philopatric species. - In: Long-term field studies of primates (Kappeler, P.M. \& Watts, D.P., eds). Springer, Berlin, p. 143-433. 
Furuichi, T., Idani, G., Ihobe, H., Kuroda, S., Kitamura, K., Mori, A., Enomoto, T., Okayasu, N., Hashimoto, C. \& Kano, T. (1998). Population dynamics of wild bonobos (Pan paniscus) at Wamba. — Int. J. Primatol. 19: 1029-1043.

Gilby, I.C. (2006). Meat sharing among the Gombe chimpanzees: harassment and reciprocal exchange. - Anim. Behav. 71: 953-963.

Gilby, I.C., Emery Thompson, M., Ruane, J.D. \& Wrangham, R.W. (2010). No evidence of short-term exchange of meat for sex among chimpanzees. - J. Hum. Evol. 59: 44-53.

Gomes, C.M. \& Boesch, C. (2009). Wild chimpanzees exchange meat for sex on a long-term basis. - PLoS ONE 4: e5116.

Goodall, J. (1986). The chimpanzees of Gombe: patterns of behavior. — Harvard University Press, Cambridge, MA.

Hamilton, W.D. (1964). Genetical evolution of social behaviour I. — J. Theor. Biol. 7: 1-16.

Hare, B. \& Kwetuenda, S. (2010). Bonobos voluntarily share their own food with others. Curr. Biol. 20: R230-R231.

Hare, B., Melis, A.P., Woods, V., Hastings, S. \& Wrangham, R. (2007). Tolerance allows bonobos to outperform chimpanzees on a cooperative task. - Curr. Biol. 17: 619-623.

Hashimoto, C. (1997). Context and development of adult behavior of wild bonobos (Pan paniscus) at Wamba, Zaire. - Int. J. Primatol. 18: 1-21.

Hashimoto, C., Tashiro, Y., Hibino, E., Mulavwa, M., Yangozene, K., Furuichi, T., Idani, G. \& Takenaka, O. (2008). Longitudinal structure of a unit-group of bonobos: male philopatry and possible fusion of unit-groups. - In: The bonobos: behavior, ecology, and conservation (Furuichi, T. \& Thompson, J., eds). Springer, New York, NY, p. 107-119.

Hemelrijk, C.K. (1990). Models of, and tests for, reciprocity, unidirectionality and other social interaction patterns at a group level. - Anim. Behav. 39: 1013-1029 (for MatrixTester, see http://www.rug.nl/research/behavioural-ecology-and-self-organization/people/ hemelrijk).

Hirata, S., Yamamoto, S., Takemoto, H. \& Matsuzawa, T. (2010). A case report of meat and fruit sharing in a pair of wild bonobos. — Pan Africa News 17: 21-23.

Hockings, K.J., Humle, T., Anderson, J.R., Biro, D., Sousa, C., Ohashi, G. \& Matsuzawa, T. (2007). Chimpanzees share forbidden fruit. — PLoS ONE 2: e886.

Hohmann, G. \& Fruth, B. (2003). Intra- and inter-sexual aggression by bonobos in the context of mating. - Behaviour 140: 1389-1413.

Hohmann, G. \& Fruth, B. (2008). New records on prey capture and meat eating by bonobos at Lui Kotale, Salonga National Park, Democratic Republic of Congo. - Folia Primatol. 79: 103-110.

Idani, G. (1991). Social relationships between immigrant and resident bonobo (Pan paniscus) females at Wamba. - Folia Primatol. 57: 83-95.

Idani, G., Kuroda, S., Kano, T. \& Asato, R. (1994). Flora and vegetation of Wamba forest, Central Zaire with reference to bonobo (Pan paniscus) foods. - Tropics 3: 309-332.

Idani, G., Mwanza, N., Ihobe, H., Hashimoto, C., Tashiro, Y. \& Furuichi, T. (2008). Changes in the status of bonobos, their habitat, and the situation of humans at Wamba in the Luo Scientific Reserve, Democratic Republic of Congo. - In: The bonobos: behavior, 
ecology, and conservation (Furuichi, T. \& Thompson, J., eds). Springer, New York, NY, p. 291-302.

Ihobe, H. (1992). Observations on the meat-eating behavior of wild bonobos (Pan paniscus) at Wamba, Republic of Zaire. - Primates 33: 247-250.

Ingmanson, E. \& Ihobe, H. (1992). Predation and meat eating by Pan paniscus at Wamba, Zaire. - Am. J. Phys. Anthropol. 35(Suppl. 14): 93.

Jaeggi, A.V., Burkart, J.M. \& van Schaik, C.P. (2010b). On the psychology of cooperation in humans and other primates: combining the natural history and experimental evidence of prosociality. — Philos. Trans. Roy. Soc. B 365: 2723-2735.

Jaeggi, A.V., Stevens, J.M.G. \& van Schaik, C.P. (2010a). Tolerant food sharing and reciprocity is precluded by despotism in bonobos but not chimpanzees. - Am. J. Phys. Anthropol. 143: 41-51.

Jaeggi, A.V. \& van Schaik, C.P. (2011). The evolution of food sharing in primates. — Behav. Ecol. Sociobiol. 65: 2125-2140.

Kano, T. (1980). Social behavior of wild pygmy chimpanzees (Pan paniscus) of Wamba: a preliminary report. — J. Hum. Evol. 9: 243-260.

Kano, T. (1992). The last ape: pygmy chimpanzee behavior and ecology. — Stanford University Press, Stanford, CA.

Kawanaka, K. (1982). Further studies on predation by chimpanzees of the Mahale Mountains. — Primates 23: 364-384.

Kuroda, S. (1980). Social behavior of the pygmy chimpanzees. — Primates 21: 181-197.

Kuroda, S. (1984). Interaction over food among pygmy chimpanzees. — In: The pygmy chimpanzee: evolutionary biology and behavior (Susman, R.L., ed.). Plenum Press, New York, NY, p. 301-324.

Mitani, J.C. \& Watts, D.P. (1999). Demographic influences on the hunting behavior of chimpanzees. - Am. J. Phys. Anthropol. 109: 439-454.

Mitani, J.C. \& Watts, D.P. (2001). Why do chimpanzees hunt and share meat? - Anim. Behav. 61: 915-924.

Nishida, T., Hasegawa, T., Hayaki, H., Takahata, Y. \& Uehara, S. (1992). Meatsharing as a coalition strategy by an alpha male chimpanzee? - In: Topics in primatology, Vol. 1: human origins (Nishida, T., McGrew, W.C., Marler, P., Pickford, M. \& de Waal, F.B.M., eds). University of Tokyo Press, Tokyo, p. 159-174.

Ohashi, G. (2007). Papaya fruit sharing in wild chimpanzees at Bossou, Guinea. — Pan Africa News 14: 14-16.

R Core Team (2014). R: a language and environment for statistical computing. - R Foundation for Statistical Computing, Vienna, available online at http://www.R-project.org/.

Slocombe, K.E. \& Newton-Fisher, N.E. (2005). Fruit sharing between wild adult chimpanzees (Pan troglodytes schweinfurthii): a socially significant event? - Am. J. Primatol. 65: 385-391.

Stevens, J.R. (2004). The selfish nature of generosity: harassment and food sharing in primates. - Proc. Roy. Soc. Lond. B: Biol. Sci. 271: 451-456.

Stevens, J.R. \& Gilby, I. (2004). A conceptual framework for nonkin food sharing: timing and currency of benefits. - Anim. Behav. 67: 603-614. 
Stevens, J.R. \& Hauser, M.D. (2004). Why be nice? Psychological constraints on the evolution of cooperation. - Trends. Cogn. Sci. 8: 60-65.

Surbeck, M. \& Hohmann, G. (2008). Primate hunting by bonobos at LuiKotal, Salonga National Park. - Curr. Biol. 18: R906-R907.

Surbeck, M. \& Hohmann, G. (2013). Intersexual dominance relationships and the influence of leverage on the outcome of conflicts in wild bonobos (Pan paniscus). - Behav. Ecol. Sociobiol. 67: 1767-1780.

Surbeck, M., Mundry, R. \& Hohmann, G. (2011). Mothers matter! Maternal support, dominance status and mating success in male bonobos (Pan paniscus). — Proc. Roy. Soc. Lond. B: Biol. Sci. 278: 590-598.

Tan, J. \& Hare, B. (2013). Bonobos share with strangers. — PLoS ONE 8(1): e51922.

Teleki, G. (1973). The predatory behavior of wild chimpanzees. — Bucknell University Press, Lewisburg, PA.

Ueno, A. \& Matsuzawa, T. (2004). Food transfer between chimpanzee mothers and their infants. - Primates 45: 231-239.

Warneken, F., Hare, B., Melis, A.P., Hanus, D. \& Tomasello, M. (2007). Spontaneous altruism by chimpanzees and young children. - PLoS Biol. 5: 1414-1420.

White, F.J. (1994). Food sharing in wild pygmy chimpanzees, Pan paniscus. — In: Current primatology, Vol. II: social development, learning and behavior (Roeder, J.J., Thierry, B., Anderson, J.R. \& Herrenschmidt, N., eds). Universite Louis Pasteur, Strasbourg, p. 1-10.

White, F.J. \& Wood, K.D. (2007). Female feeding priority in bonobos, Pan paniscus, and the question of female dominance. - Am. J. Primatol. 69: 837-850.

Wrangham, R.W. (1975). The behavioural ecology of chimpanzees in Gombe National Park, Tanzania. - PhD thesis, Cambridge University, Cambridge.

Yamamoto, S., Humle, T. \& Tanaka, M. (2009). Chimpanzees help each other upon request. - PLoS ONE 4: e7416.

Yamamoto, S., Humle, T. \& Tanaka, M. (2012). Chimpanzees' flexible targeted helping based on an understanding of conspecifics' goals. — Proc. Natl. Acad. Sci. USA 109: 35883592.

Yamamoto, S., Humle, T. \& Tanaka, M. (2013). Basis for cumulative cultural evolution in chimpanzees: social learning of a more efficient tool-use technique. - PLoS ONE 8: e55768.

Ydenberg, R.C. (1994). The behavioral ecology of provisioning in birds. - Ecoscience 1: $1-14$. 